\title{
Investor Sentiment and the Impact on Four Main Cities of China's Real Estate Market
}

\author{
Yi-Chang Chen $^{1}$ \\ ${ }^{1}$ School of Finance and Accounting \\ Fuzhou University of International Studies and Trade, China
}

\author{
Zhengdong $\mathrm{Wu}^{3 *}$ \\ ${ }^{3}$ Department of Computer Science and Engineering, \\ Nanfang College of Sun Yat-sen University, China \\ *Corresponding author
}

\begin{abstract}
In this paper, we test herd effect and the impact of investor's sentiment on four main cities of China's real estate market. We use CSAD model with sentiment indicators and explore the correlation between emotional indicators and housing index. We find that there is a significant herding effect in the real estate market, including Beijing, Shanghai, Guangzhou, and Shenzhen. The eight sentiment variables had varying degrees of influence on all four cities. Overall, investor sentiment is relatively stable affected by the macroeconomic regulation and control.
\end{abstract} index

Keywords-Herd effect; Investor sentiments; CSAD; Housing

\section{INTRODUCTION}

Herd behavior is a phenomenon in behavioral finance, which refers to the tendency of individuals to combine personal opinions, judgments, and behaviors with the views and behaviors of groups. Many researchers have explored the impact of market sentiment and herd behavior. However, in the study of the real estate market, there is less concern about sentiment variables and herd behavior. But before studying the relationship between emotional variables and house price index, it is necessary to regard herd behavior as a major premise and basic condition.

Bikhchandani and Sharma (2001) pointed out that herd behavior affects individual investment behavior, leading to decisions to imitate or blindly follow others and abandon preexisting information and decisions. Chang et al. (2000) modified the CSSD regression model and the capital asset pricing model CAPM and created the CSAD model as a way to explore advanced economies such as the United States, Hong Kong, and some developing economies such as South Korea and Taiwan. Gu and Zhang (2014) find that interest rate is the Granger cause of real estate prices. However, interest rate regulation on real estate prices is not significant, so there is a long-term stable positive equilibrium relationship between the deposit rate and real estate prices.

In this paper, we refer to the basic idea of CSAD method of Chang et al. (2000) to test the herd behavior in the real estate market. We use the CSAD model to test the herd effect of the real estate price index, and the conclusions are compared with

\author{
Shilin Liang ${ }^{2}$ \\ ${ }^{2}$ Accounting School, Nanfang College of Sun Yat-sen \\ University, China
}

\author{
Jiaqi $\mathrm{Luo}^{4}$ \\ ${ }^{4}$ Accounting School, Nanfang College of Sun Yat-sen \\ University, China
}

the other eight sentiment variables to do the Pearson correlation analysis to test the variables that have the greatest impact on the real estate price index and analyze the reasons. The method adopted by $\mathrm{Ke}$ (2012) research team is to calculate the monthly house price return rate, and then use the CSAD model to test it. The CSAD is measured to be significant, which proves that the real estate market has a herd effect. However, we use the real estate price index to test.

This paper mainly examines the impact of sentiment variables on the house price index in the real estate market. We test whether there is a herd effect in the real estate market, and then use the herd effect as a sentiment variable to conduct a relevant test on housing prices.

The paper is organized as follows: Section 2 focuses on a review of previous studies. Section 3 illustrates the method and data. Empirical analysis is shown in Section 4, and Section 5 offers conclusions.

\section{LITERATURE REVIEW}

Herd behavior is an irrational behavior, usually triggered by uncertainty. Bikhchandani and Sharma (2001) pointed out that herd behavior affects individual investment behavior, leading to decisions to imitate or blindly follow others and abandon preexisting information and decisions. Nofsinger and Sias (1999) define the behavior as the trend of investors flocking in the same direction at a specific time. Christie and Huang (1995) used the CSSD regression model to find evidence of herd behavior when studying the herd behavior of the New York Stock Exchange or the American Stock Exchange. Chang et al. (2000) modified the CSSD regression model and the capital asset pricing model CAPM and created the CSAD model as a way to explore advanced economies such as the United States, Hong Kong, and some developing economies such as South Korea and Taiwan.

Some studies have confirmed the impact of herd behavior (Abraham and Hendershot, 1994; Baddeley, 2005; Banerjee, 1992), Baker and Yuan (2012), Case and Shiller (1988), Du and Liu, 2007; Dong et al., 2014; Wang et al, 2013 and Tan et al., 2008) found that herd behavior is a factor affecting A-share and B-share transactions. Mohammad and Majid (2002) used the UK 
as a research object and believed that monetary policy instruments such as interest rate instruments and credit scale have a significant impact on real estate prices.

Gu and Zhang (2014) find that interest rate causes real estate prices. However, interest rate regulation on real estate prices is not significant, so there is a long-term stable positive equilibrium relationship between the deposit rate and real estate prices.

\section{METHOD}

\section{A. CSAD model}

The empirical analysis of real estate herd behavior is more difficult because the real estate market does not have the same high-frequency transaction data as the financial securities market, such as securities prices and trading volumes, and financial securities markets. In addition, taking into account the differences in the level of economic development, urban development conditions, resource complexity and demographic characteristics of various provinces and cities in China's real estate market. Therefore, we use the basic idea of the CSAD method of Chang et al to test the herd behavior of the real estate market, and use the method of $\mathrm{Ke}$ (2012), and some materials to assist the real estate herding effect test.

Ke (2012) proposed to measure the absolute deviation of the cross-section of the real estate market in the real estate market by calculating the real estate yields of major provinces and cities, and to measure the consistency and concentration of real estate investors by the absolute deviation of cross-section. For example, when the real estate market in each province is treated equally by investors, there may be a herding effect. Here, we use the real estate price index as the raw dataset and calculate it to test the herd effect of the real estate market.

Using the CSAD method of Chang et al. (2000), the existence model of herd behavior in the real estate market:

$$
E\left(C S A D_{t}\right)=\frac{1}{N} \sum_{i=1}^{N} \mid E\left(R_{i, t}\right)-E\left(\overline{R_{t}}\right)
$$

Where $\mathrm{Ri}, \mathrm{t}$ is the $\mathrm{i}$-th province in the $\mathrm{t}$-term real estate rate of return (i.e., house price yield), $\bar{R}_{t}$ indicating the overall yield of the national real estate market in the t-th period, so the corresponding beta coefficient should be:

$\overline{R_{t}}$ represents the total rate of return of the national real estate market in the t-th period, so the corresponding beta coefficient of $\overline{R t}$ should be:

$$
\overline{\beta_{t}}=\frac{1}{N} \sum_{i=1}^{N} \beta_{i, t}
$$

The capitalization rate is determined according to the CSAD model, and the following relationships are established:

$$
E\left(R_{i, t}\right)=R f+\beta_{i, t}\left[E\left(R_{m, t}\right)-R f\right]
$$

$$
E\left(\overline{R_{t}}\right)=R f+\overline{\beta_{t}}\left[E\left(R_{m, t}\right)-R f\right]
$$

Where Rm,t is the market combined rate of return and Rf is the risk-free rate of return, further adjustments are available

$$
\left|E\left(R_{i, t}\right)-E\left(\bar{R}_{t}\right)\right|=\left|\beta_{i, t}-\bar{\beta}_{t}\right|\left[E\left(R_{m, t}\right)-R f\right]
$$

Therefore, CSAD can be expressed in the following relationship:

$$
E\left(C S A D_{t}\right)=\frac{1}{N} \sum_{i=1}^{N}\left|\beta_{i, t} \bar{\beta}_{t}\right|\left[E\left(R_{m, t}\right)-R f\right]
$$

For the above expression, find the first and second derivatives of $E\left(R_{m, t}\right)$, as follow:

$$
\begin{aligned}
& \frac{\partial E\left(C S A D_{t}\right)}{\partial E\left(R_{m, t}\right)}=\frac{1}{N} \sum_{i=1}^{N}\left|\beta_{i, t}-\overline{\beta_{t}}\right|>0 \\
& \frac{\partial^{2} E\left(C S A D_{t}\right)}{\partial E\left(R_{m, t}\right)^{2}}=0
\end{aligned}
$$

Chang et al. (2000) pointed out that in the case of the establishment of the traditional CAPM, E $\left(C S A D_{t}\right)$ will be a linear function of the market portfolio expected return rate $\mathrm{E}(\mathrm{Rm}, \mathrm{t})$. Therefore, when $\mathrm{E}(\mathrm{Rm}, \mathrm{t})$ rises, $\mathrm{E}\left(C S A D_{t}\right)$ will rise linearly. However, if there is a herding effect, when the price of assets in the market rises sharply, this will lead to a linear incremental relationship between $\mathrm{E}\left(C S A D_{t}\right)$ and $E\left(R_{m, t}\right)$ because individuals imitate each other's buying and selling behavior. Once again, there is a linear relationship between the two. This can be used to test the behavior of the herd behavior in the real estate market, as shown in Equation:

$$
C S A D_{t}=\gamma_{0}+\gamma_{1}\left|R_{m, t}\right|+\gamma_{2} R_{m, t}^{2}+\varepsilon_{t}
$$

When it is significantly negative, it indicates the existence of herd behavior; on the contrary, when it is not significantly negative, it indicates that the herd behavior is not significant.

\section{B. Variables selection}

In this paper, the correlation formula is analyzed by pearson correlation. The house price index is used as the variable and the eight emotional variables are used as the arguments to investigate the correlation between the two. Among them, 8 emotional variables have certain literature support. We set 8 arguments, including: interest rate (Ir), national housing prosperity index $(\mathrm{Ci})$, consumer price index $(\mathrm{CPI})$, per capita GDP, credit line (NCL), consumer satisfaction index (CCI), money supply (MS), CSAD .

Gu and Zhang (2014) used X1 to test real estate prices. Yi (2009) used the National Housing Climate Index Ci to test real estate prices. Guo (2007) used the consumer price index CPI to test real estate prices. Wang (2015) used real GDP per capita to test real estate prices. Wang (2017) used the credit line NCL to test real estate prices. Guo (2007) used the Consumer Satisfaction Index CCI to test real estate prices. Lu (2018) used the money supply MS to test real estate prices. Ke (2012) used 
real estate price yield and other indicators to test the herd effect of the real estate market. This paper quotes its data and indicators as an index of emotional variables.

In the following table, we use the RSI for the average house price index; the monthly average interest rate is expressed by Ir; the consumer satisfaction index is expressed by CCI; the money supply is expressed by MS; the new credit loan amount is expressed by NCL; It is expressed by $\mathrm{Ci}$; the consumer price index is expressed by $\mathrm{CPI}$; the average index return rate $(\mathrm{Y})$ is represented by $\mathrm{Rm}$.

\section{The regression}

In this paper, $C S A D_{t}$ and 7 sentiment variables are subjected to regression analysis to study the degree of fitting of the model. This regression analysis is to study the relationship between the mean value of real estate price index and the number of variables due to variables, mainly through the establishment of $R_{\text {housing,t }}$ and its influence. The regression model is:

$$
\begin{aligned}
R_{\text {housing }, \mathrm{t}}= & c+C S A D_{t}+I r_{t}+C C I_{t}+M S_{t}+N C L_{t} \\
& +C i_{t}+C P I_{t}+R I X_{t}+\varepsilon_{\mathrm{t}}
\end{aligned}
$$

\section{DATASET AND EMPIRICAL RESULTS}

It can be seen from Table 1 and Table 2 that the monthly average interest rate, consumer satisfaction, money supply, and household consumption index are negatively correlated with the real estate price index. These four sentiment variables are macroeconomic indicators. In Table 3, the herd effect measured in this paper is significant at $1 \%$ level (see $\gamma_{2}$ ). This paper speculates that due to the large scale of national macro-control, the herd effect cannot be measured in the real estate price index. This is also one of the shortcomings of this article. Combining Tables 1 and 2, we know that the impact of macroeconomic regulation on real estate prices is the biggest. At the same time, China's capital market and real estate market are fundamentally not in the free market, so compared with the European and American markets, out of the herd effect is more difficult.

TABLE I HERDING RESULTS

\begin{tabular}{lllll}
\hline Variable & Coefficient & Std. Error & t-Statistic & Prob. \\
\hline $\mathrm{C}$ & 0.297 & 0.025 & 11.463 & 0 \\
$\gamma_{1}$ & -0.123 & 0.266 & -0.463 & 0.6438 \\
$\gamma_{2}$ & 1.478 & 0.473 & 3.125 & 0.0024 \\
\hline
\end{tabular}

TABLE II RESULTS OF SENTIMENTS FOR HOUSING INDEX

\begin{tabular}{|l|l|l|l|l|l|}
\hline & $\mathrm{c}$ & $\mathrm{Ir}$ & $\mathrm{CCI}$ & $\mathrm{MS}$ & $\mathrm{NCL}$ \\
\hline Coefficient & $138.05^{* * *}$ & $-0.462 * * *$ & $-0.096^{* * *}$ & 0.000 & 0 \\
\hline t-value & $(-7.44)$ & $(-2.90)$ & $(-2.92)$ & $(-0.37)$ & $(-0.50)$ \\
\hline (cont.) & & & & & \\
\hline & GDP & $\mathrm{Ci}$ & CPI & $\mathrm{Rm}$ & \\
\hline Coefficient & 0 & 0.182 & -0.422 & 1.72 & \\
\hline t-value & $(-1.14)$ & $(-1.76)$ & $(-1.69)$ & $(-3.62)$ & \\
\hline
\end{tabular}

\section{CONCLUSION}

In this paper, we examine the relationship between the herd effect and the sentiment variables of real estate market and real estate prices. After observing the relationship between the CSAD model and the house price index, by referring to the empirical results obtained by Chang et al. (2000) and Ke (2012), the sheep measured in this paper under the premise of using the CSAD model test. The group effect is not significant. It is speculated that the Chinese market is a non-free market, and the country's macro-control is more powerful. Therefore, it is more difficult to use the real estate price index to measure the real estate herding effect. Even if the measured herd effect is not significant, we use it as one of the sentiment variables to test its relevance to the real estate price index. In the correlation analysis, another 7 sentiment variables were added. Among the other seven emotional variables, monthly mean interest rate, consumer satisfaction index, money supply and household consumption index were significantly negatively correlated. In summary, through these emotional variables, we can see that China's real estate prices are still the most affected by the state's macroeconomic regulation and control. We hope that while housing prices are rising, the country's macro-control policies can increase regulation and control, and reduce real estate price bubbles. Avoid excessive real estate price bubbles and create a new economic crisis. 


\section{REFERENCES}

[1] Abraham, J. M., \& Hendershott, P. H. (1994). Bubbles in metropolitan housing markets (No. w4774). National Bureau of Economic Research.

[2] Bikhchandani, S., Sharma. S. (2001), Herd Behavior in Financial Markets. IMF Staff Papers, 47(3), 279-310.

[3] Baddeley, M. (2005). Housing bubbles, herds and frenzies: evidence from British housing markets.

[4] Banerjee, A. V. (1992). A Simple Model of Herding Behaviour. Quarterly Journal of Economics, 107(3)

[5] Baker, M., Wurgler, J., \& Yuan, Y. (2012). Global, local, and contagious investor sentiment. Journal of financial economics, 104(2), 272-287.

[6] Case, K. E., \& Shiller, R. J. (1988). The efficiency of the market for singlefamily homes.

[7] Chang, E. C., Cheng, J. W., \& Khorana, A. (2000). An examination of herd behavior in equity markets: An international perspective. Journal of Banking \& Finance, 24(10), 1651-1679.

[8] Christie, W.G., Huang, R.D. (1995), Following the Pied Piper: Do Individual Returns Herd around the Market? . Financial Analysts Journal, 51(4), 31-37.

[9] Du, M. J., \& Liu, X. H. (2007). Expectation of RMB appreciation and real estate price changes [J]. World Economy, 1(1): 81-88. (in Chinese)

[10] Dong, Q., Sun, N. N., \& Li, W. (2014). Real estate price forecast based on online search data [J]. Statistical Research, 31(10): 81-88.

[11] Gu, H. F., \& Zhang, Y. Z. (2014). Monetary Policy and Real Estate Price Regulation: Theory and China Experience [J]. Economic Research, 1(1): $29-43$

[12] Guo, H. L. (2007). Research on China Real Estate Confidence Index. Harbin Institute of Technology Press.

[13] Ke, Y., \& Huang, J. (2012). Research on Herding Behavior of Real Estate Market Based on CSAD Nonlinear Model[J]. Economics and Finance, 24(9): 19-25. (in Chinese)

[14] Lu, C., \& Zhu, J. M. (2018). The impact of exchange rate and money supply on the price of commercial housing in the country. Journal of Science and Technology, 38(7).

[15] Nofsinger, J. R., Sias W. (1999), Herding and Feedback Trading by Institutional and Individual Investors. The Journal of Finance, 54(6), 2263-2295.

[16] Wang, Q. F., (2015). Research on Real Estate Price, Economic Growth and Credit Expansion in China: Based on the Analysis of Real Estate Dual Asset Attributes[J]. Financial Research,10(4):32-44. (in Chinese)

[17] Wang Y. Q., Zhu, Q. G., \& Tan, Z. D. (2013). Research on China's Real Estate Market Fluctuation: Two-sector DSGE Model Based on Bayesian Estimation[J]. Financial Research, 393(3): 101-113 (in Chinese)

[18] Wang, X. X., \& Yao, W. (2017). Credit rationing analysis of real estate supply and demand equilibrium. Construction economy, 38(4). (in Chinese)

[19] Yi, C. H., \& Zhan, Y. Q. (2009). Real estate prosperity index and bank real estate credit risk measurement. Hunan University Press, 2(16) (in Chinese) 